Hispania Sacra, LIX

120, julio-diciembre 2007, 537-562, ISSN: 0018-215-X

\title{
LLAMADOS A SERVIR: LOS HOSPITALARIOS DE SAN JUAN DE DIOS EN ZACATECAS, MÉXICO EN EL SIGLO XVII
}

POR

\author{
Ana Mónica GonZÁlez FASANI \\ Ayudante de docencia. Universidad Nacional del Sur
}

\begin{abstract}
RESUMEN
Consolidada la Orden de San Juan de Dios en España, sus religiosos pronto fueron requeridos para pasar a tierras americanas. Con el fin de levantar hospitales llegaron a inicios del siglo XVII y se organizaron en tres provincias: una que abarcaría el virreinato de Nueva España y de ultramar, la otra el virreinato del Perú y una tercera, la denominada Tierra Firme. A cuatro años de instalados en México, fueron solicitados en la populosa y rica ciudad minera llamada Nuestra Señora de los Zacatecas.
\end{abstract}

PALABRAS ClAVE: hospital, enfermedades, caridad, minería, San Juan de Dios, Zacatecas

\begin{abstract}
Consolidated the Order of San Juan of God in Spain, their religious soon were required to pass to American lands. With the purpose of lifting hospitals they arrived to beginnings of the XVII century and they were organized in three counties: one that would embrace the viceroyalty of New Spain and of overseas, the other one the viceroyalty of the Peru and a third, the denominated Mainland. To four years of having installed in Mexico, they were requested in the populous and rich mining city call Our Mrs. of the Zacatecas.
\end{abstract}

KEY WORDS: hospital, deseases, charity, mining, San Juan de Dios, Zacatecas

Recibido/Received 10-04-2007

Aceptado/Accepted 13-06-2007

«Sigue vivo. Su edad, quinientos años. Medio milenio lleva Juan de Dios traspasando horizontes con la afanosa constancia de la santidad. Pero no se trata sólo de cinco siglos 
de historia, sino de cinco siglos de mantenido presente junto al hombre que sufre. Mucho tiempo ha pasado desde aquel amanecer de $1495 \mathrm{y}$, sin embargo, sigue siendo un ayer mismo en la interminable andadura de la Hospitalidad» ${ }^{\text {. }}$

Con estas palabras se inicia el editorial de la revista que los Hermanos Hospitalarios publicaron en homenaje a su fundador.

En efecto, Juan de Dios sigue vivo en el hermano que ha dispuesto caminar cada día como una nueva entrega en la estremecida geografía del dolor. El ejemplo sembrado por el santo ha provocado y provoca aún hoy, una expansiva germinación de decisiones generosas, un semillero de incesantes respuestas renovadas.

En la primera Epístola a los Corintios el apóstol Pablo escribe uno de los más bellos elogios de la caridad. La caridad es amor, amor a Dios a causa de su perfección infinita y amor al prójimo, por amor a Dios. Quien dice amor dice, entonces, relación de un ser con otro. El amor es esa actividad relacional, afectiva, que tiende a unir realmente al sujeto que ama con el objeto amado, por eso, en la caridad, la persona atrae hacia sí a quien ama. Amar se vuelve, desde esta perspectiva, una necesidad natural: es amando como cada ser entra en relación con su semejante y se completa ${ }^{2}$. Y cuanto más se ame al Ser Supremo, dador de todo bien, más cerca estará la persona de encontrar su felicidad en la felicidad del otro.

Entre las personas que vivieron a imitación de Cristo, como humildes siervos, intentando comunicar en palabra y acto su mensaje, se encontraba Juan Ciudad, más conocido como Juan de Dios. Granada fue la ciudad que amó y escogió para ministrar. Pero la granada también es un fruto, y éste simboliza las perfecciones divinas en sus efectos innumerables ${ }^{3}$. La granada era el corazón de Juan de Dios hecho fruto; así como Jesús dio su vida por todos, Juan pudo entregar la suya por los necesitados.

Juan de Dios supo ver en el prójimo a un hermano, y en el cuerpo de éste a otra criatura hecha a imagen y semejanza del Creador. Por eso amó a las personas, sobre todo al necesitado y miserable en cuerpo y alma, y buscó para él el alivio necesario. Al cuerpo enfermo intentó sanarlo, al alma atormentada le acercó la salvación, y dio dignidad y tranquilidad al moribundo en el tránsito de su muerte. Éste es el carisma de la Orden Hospitalaria.

Su nombre era Juan Ciudad, y por mucho tiempo se creyó que había nacido en Montemor-o-Novo, Portugal, en el año 1495; hoy en día, luego de re-

\footnotetext{
${ }^{1}$ Jesús CARRASCO, O. H., «Su edad, quinientos años», Hermanos Hospitalarios. Boletín Informativo, 198, (1995) p. 138.

2 «L'amour du prochain», Cahiers de la vie spirituelle, 1954, p. 119.

3 J. Chevalier y A. Gheerbrant, Diccionario de Símbolos, Barcelona, 1993, p. 538.
} 
novados estudios no cabe duda de que nació en Casarrubios del Monte, Toledo, España ${ }^{4}$.

En todo momento practicó Juan de Dios una vida de obediencia y amor espiritual. Lo mismo pidió a quienes quisieran ir en pos de él, advirtiéndoles que el camino elegido no sería fácil, y así lo comunicó en la respuesta a la carta que le escribiera Lucas Bautista, que le había manifestado deseos de acompañarlo en su amorosa tarea en el hospital de Granada. Esta advertencia, después incluida en las primeras páginas del libro rector de la comunidad, pone de manifiesto el fervor religioso que sustentaba y la responsabilidad de la vida conventual hospitalaria ${ }^{5}$.

No sólo la salud del cuerpo importaba a Juan de Dios sino la del alma, por ello disponía que recibieran todos los necesitados los santos sacramentos y que con piadosas exhortaciones se dispusiesen para la vida eterna.

El primer compañero dispuesto a cumplir con la dura e intensa tarea de ayudar y curar al necesitado fue el hermano Antón Martín quien, además, fue el primer discípulo en el sentido estricto, dado que se convirtió tras escuchar una predicación del santo en la calle de la Colcha ${ }^{6}$, y el reconocido fundador del hospital de Madrid. Otros seguidores fueron Pedro de Ugarte, Rodrigo de Sigüenza, Sebastián Arias, Pedro Pecador ${ }^{7}$, Pedro Soriano, Melchor de los Reyes,

\footnotetext{
${ }^{4}$ José Luis MarTínEZ GiL, «Sobre el nacimiento y procedencia de San Juan de Dios y su obra», Hispania Sacra, 117 (2006), p. 77.

51 Acuérdate de nuestro Señor Jesucristo y de su santísima pasión, que dio bienes por males. Así has de hacer tú, hijo mío, cuando te veas en la casa de Dios. 2 Si te determinas a venir, ha de ser al instante, y te has de guardar de las mujeres, como del Diablo. 3 Si has de venir aquí, has de ser obediente, y trabajar mucho más de aquello que has trabajado, pero en el servicio de Dios, y has de ser muy solícito en el servicio de los pobres. $4 \mathrm{Si}$ vinieres, resuélvete a hacer algún fruto a Dios, dejando la piel en memoria de san Bartolomé, que habiendo sido desollado, cargó con la suya sobre las espaldas. Y si te resuelves a venir, te advierto no ha de ser a divertirte, sí a trabajar, porque al hijo más amado se le dan los mayores trabajos. 5 No dejarás todos los días de tu vida de tener a Dios delante de tus ojos, y de oír siempre la santa misa entera. $6 \mathrm{Si}$ fuere posible, te confesarás a menudo, y jamás dormirás en pecado mortal. 7 Amarás a nuestro señor Jesucristo sobre todas las cosas del mundo; porque por mucho que tú le ames, mucho más te ama a ti. 8. Ten siempre caridad, porque donde no hay caridad no está Dios, el cual se halla en todo lugar. Regla de San Agustín N. P. Obispo y Doctor de la Iglesia. Constituciones de la Orden de la Hospitalidad de S Juan de Dios N. P. confirmadas por la santidad de Urbano Papa VIII en 9 de noviembre de 1640. Devajo de la protección siempre de sus Mag. Católicas con las adicciones hechas en el Capitulo General de 9 de Febrero de 1738 en que van inclusas las Actas confirmadas por el Sr, Inocencio IX. Aprobadas por la Santidad de Clemente XII y por Nuestro Santísimo P. Benedicto Papa XIV en 20 de Febrero de 1741, Madrid, 1744, p. 8.

${ }^{6}$ Dimensión apostólica de la Orden Hospitalaria de San Juan de Dios, Barcelona, 1982, p. 22.

${ }^{7}$ Pedro Pecador nació en Ubrique, Cádiz, hacia el 1500, y murió en Mondéjar en 1580. Era escultor, pero resuelto a abrazar la vida del místico, se retiró al desierto y luego hizo peregrinación a Roma. Se sabe también que fundó los hospitales de Sevilla, Málaga y Antequera, en los cuales dejó hermanos
} 
Cebrián de la Nada y Juan Pecador. De algunos de estos hombres se sabe poco, pero los nombres que tomaron demuestran una clara conciencia de su debilidad humana, un arrepentimiento sincero de sus acciones pasadas, la renuncia a la vida mundana en que estaban envueltos, y un anhelo de perdón a alcanzar mediante la penitencia y la mortificación de la carne.

\section{«HACED BIEN, HERMANOS»8}

En tanto que orden regular, la de San Juan de Dios estaba obligada a guardar los tres votos monásticos: obediencia, pobreza y castidad, pero dado su carácter eminentemente caritativo, se comprometía con un cuarto, el de hospitalidad, por el cual se obligaban al cuidado y la asistencia de los pobres con la mayor solicitud y caridad. Firmes en el evangelio, obedecían a Jesucristo quien dice: «De cierto os digo que en cuanto lo hicisteis a uno de estos mis hermanos más pequeños, a mí lo hicisteis». Aceptaban la pesada carga de visitar a los enfermos por la mañana y enterarse cómo habían pasado la noche; acercarse a ellos a la hora tercia, acompañando al médico; nuevamente a la hora sexta, o a medio día, para servirles los alimentos; y por la noche, otra vez, la última visita. También dentro de sus obligaciones estaba la de socorrer espiritual y corporalmente al agonizante hasta el momento de su muerte ${ }^{9}$. Sobre la hospitalidad decían sus manuales:

«Si se mira la hospitalidad que profesamos, es ella una cosa tan divina que agravio se hiciera a sus excelencias en quererlas manifestar con lenguas de hombres [...] Una de las mayores virtudes de que son alabados los Santos Patriarcas antiguos, es la hospitalidad [...] El gloriosísimo Pablo en sus epístolas recomendaba a los fieles esta altísima virtud, principalmente escribiendo a los Hebreos, diciendo no se olviden de ella, por haber sucedido al que la ejercitó, recibir ángeles» ${ }^{10}$.

mayores a cargo. Tenía como unos setenta años cuando pidió recibir los hábitos en el Convento Hospital de Granada. Los obtuvo del mencionado fray Rodrigo de Sigüenza, prior del citado convento. Sigüenza era valenciano, y tras llevar una vida militar, conoció la obra de los primeros compañeros de Juan de Dios en Granada; prendado por la solicitud con que atendían a los enfermos, por la caridad y modestia con que vivían, pidió entrar a la comunidad en 1555. Se cree que fue él quien consiguió del papa Pío V la aprobación. Seguidores y compañeros de Pedro Pecador fueron Pedro de Ugarte, otro malagueño, a quien se le atribuye la fundación del hospital de Ronda, y Juan Pecador, nacido en Jaén, de una familia de trabajadores jerezanos, quien recibió el hábito de manos de Pedro Pecador, para fundar, a su vez, el hospital de Utrera. Pedro Soriano era cordobés, y hacia los cuarenta años (1555) tomó el hábito en el convento de Granada; es reconocido como el primer general de la orden e impulsor de la misma a tierras extranjeras, dado que fundó un hospital en Nápoles, donde murió. Idem.

${ }^{8}$ Se inician con estas palabras las Constituciones de la Orden de San Juan de Dios.

${ }^{9}$ Regla... op. cit., capítulos. LI y LII.

${ }^{10} \mathrm{~A}$. de Victoria, Instrucción de novicios del orden de la hospitalidad, con licencia en México por doña María de Benavídez, viuda de Juan de Ribera, 1693.

Hispania Sacra, LIX

120, julio-diciembre 2007, 537-562, ISSN: 0018-215-X 
Los hospitalarios estaban a diario en contacto con el cuerpo ${ }^{11}$, la enfermedad $^{12}$ y la finitud de la vida. En general, la idea que sobre la enfermedad se tenía puede ser muy bien comprendida al leer las obras que circulaban sobre dicho tema. Una, aparecida a principios del siglo XVII, comentaba:

«Represéntele cómo las enfermedades vienen de la mano de Dios, el cual las envía en castigo de nuestros pecados. Y así que el modo más breve de sanar es quitar la causa; que la paz del alma contribuye mucho a la salud del cuerpo, y que ésta es imposible tenerla si está en desgracia de Dios; que debemos apreciar más la vida del alma que la del cuerpo» ${ }^{13}$.

La enfermedad no sólo era vista como un castigo a las faltas humanas, sino también como una prueba divina que permitía al hombre ejercitar la paciencia y, a partir de ella, crecer en madurez cristiana, por ello en Recetas de espíritu para enfermos del cuerpo, un libro escrito para la Orden a fines del siglo XVII, se les recomendaba que ayudaran al enfermo a pacificar su alma, a ejercitar la virtud de la fortaleza y la paciencia, y a recibir al dolor con «afecto de que sea mortificado el cuerpo por ser enemigo del alma»14. Igualmente debía exhortársele a tolerar la enfermedad con humildad y mansedumbre, y a recibir el consuelo de los santos que padecieron dichas enfermedades para pedirles socorro e imitarlos, o para encomendarse a ellos en el momento de morir. Sobre todo, el hombre debía vivir convencido de que todo lo que le ocurría era porque Dios así lo permitía.

«Exhortamos también a todos los Hermanos de nuestra Orden para que, aplicándose a tan piadosa virtud y santa acción, bien enseñados y enterados, se dispongan a confortar

\footnotetext{
${ }^{11}$ La iglesia de la Contrarreforma refuerza la desconfianza que el magisterio ya había manifestado en los siglos medievales respecto al cuerpo, «ese abominables vestido del alma». Cuerpo despreciado del hombre pecador al que se le dice sin cesar que por el cuerpo corre el riesgo de perderse. El pecado y el miedo, el miedo al cuerpo de la mujer, sobre todo, se repiten como una letanía en forma de advertencias o de condenas. J. Gélis, A. Corbin, y J. Courtine (dir), Historia del Cuerpo, Madrid, 2005, p. 28

${ }^{12}$ Por un lado, se entendía que la posibilidad y el hecho de enfermar se debía a la vulneratio que el pecado original produjo en la naturaleza humana. Por obra de esa «herida», la naturaleza del hombre sería en todo momento susceptible de padecer enfermedad y podría reaccionar pecaminosamente (con ira, desesperación, presunción, etc) al hecho de padecerla. Por otro lado, la medicina escolástica explicaba que cada enfermedad concreta era causada por acciones puramente naturales (frío, veneno, etc) y no tenía como causa el pecado, fuera éste original o personal. D. GARCía Guillén y J. L. PESET, «La medicina en los siglos XIV-XV», en Historia Universal de la medicina, LAIN ENTRALGo (coord.) Tomo 5 (1975) 338 .

13 J. CRASSET, La dulce y santa muerte, Imprenta de José Rius, s/l, 1867.

${ }^{14}$ Recetas de Espíritu para enfermos del cuerpo, por el P. Pedro de Mercado, de la Compañía de Jesús. Dedicadas al M. R. P. Antonio Cabeça de Baca, del orden de la Hospitalidad de San Juan de Dios, Comissario General de la Provincia de Tierrafirme, y Nuevo Reyno de Granada. Año 1681.
} 
a los agonizantes, ayudándoles a bien morir y a morir como verdaderos fieles e hijos legítimos de la Santa Iglesia» ${ }^{15}$.

«Y ME SERÉIS TESTIGOS HASTA LO ÚLTIMO DE LA TIERRA» (HCH. 1:8)

La Orden de San Juan de Dios se extendió a otros países fuera de España, como Portugal, Italia (donde tuvo un gran arraigo), Francia. También se creó la provincia hospitalaria de San Miguel de Germania, que abarcaba los actuales territorios de Alemania, Austria, ex Checoslovaquia y Hungría; incluso hasta el mundo eslavo conformando la provincia de la Santísima Anunciata de Polonia. Las constituciones de la Orden, organizaban igualmente el gobierno de los hospitales en América e Indias Orientales.

El Ecuménico Concilio de Trento había declarado que todos los hospitales dependían de la Iglesia en cuanto que eran instituciones religiosas (aunque el fundador y las personas que los atendiesen fueran laicos) y que, por tanto, quedaban sujetos a la jurisdicción del ordinario eclesiástico, pero para evitar problemas con la autoridad civil, se los puso bajo la inmediata protección de los reyes ${ }^{16}$. Las consecuencias de estas declaraciones fueron trascendentes porque, al establecerse en España el Real Patronato, todos los hospitales quedaron incluidos en él.

Paralelamente, aunque las Ordenanzas de cada hospital eran hechas por sus fundadores, tenían que ajustarse a ciertas bases dadas por la Iglesia en el III Concilio Provincial Mexicano de 1585. Entre ellas pueden mencionarse: la obligación de que los hospitales fueran exclusivamente para pobres; que se diera instrucción religiosa a los enfermos; que hombres y mujeres estuvieran en salas separadas; que se registrara todo lo concerniente a la vida hospitalaria en libros; que no se recibiesen malhechores, y que todos vivieran adornados de un celo cristiano ${ }^{17}$.

En América se asentaron la provincia del Espíritu Santo, que abarcaba Nueva España, la Habana y Filipinas, se establecería en México; el de San Bernardo, que comprendía los conventos y hospitales de Tierra Firme, en Panamá; y el

15 Dimensión apostólica... op. cit., p. 87. Así se expresaba el padre Avagnale, Ordini Osservandi, en el año 1653. La cita completa dice lo siguiente: «corroborándoles en la fe, en la esperanza y en la caridad: consolándolos, como buen médico de su salud espiritual, con palabras de piedad y devoción: recordándoles el acudir a su ángel custodio y a los Santos y Santas de su devoción [...] exhortándoles a soportar con paciencia los dolores y los desasosiegos [...] invitándoles a los actos de verdadera contrición y dolor de sus pecados, ya a conformar su voluntad con el querer divino: y apartándolos de la disputa con el enemigo de la salvación humana».

${ }^{16}$ Concilio de Trento, Sesión 22 Reforma, cap. 8.

${ }^{17}$ III Concilio Provincial Mexicano, Tít. XIV, cap. III.

Hispania Sacra, LIX

120, julio-diciembre 2007, 537-562, ISSN: 0018-215-X 
de la provincia de San Rafael, que abarcaba el Virreinato del Perú, se asentaría en Lima.

Los religiosos que venían a América eran nombrados por el padre general, quien otorgaba a alguno de ellos el liderazgo del grupo hasta que llegaran a los hospitales que tenían designados.

En América y provincia de Goa (perteneciente a Portugal), los priores eran nombrados por los comisarios generales y consiliarios de cada una de las casas, juntamente con los dos frailes más antiguos de la comunidad. Cada casa podía proponer a los electores cuatro religiosos, quienes serían elegidos por voto secreto. Al igual que en la Península, quien fuera elegido prior de un hospital en Indias debía tener al menos treinta años de edad y ocho de profesión, y duraría tres años en dicha función. Pero, al parecer, por lo que se lee en el capítulo «De la elección», en América no se respetaba lo prescripto en las constituciones:

«Y por cuanto se tiene noticia, que en las Provincias de los reinos de Indias no se cumple arreglado a ley de esta Constitución, se mando con precepto formal de santa obediencia a los Comisarios Generales de ella, que observen lo prevenido en ellas sobre la elección de priores, haciéndolas canónicamente» ${ }^{18}$.

Para que, en todo momento, las Indias Orientales y Occidentales estuviesen representadas en las reuniones de capítulo general, los comisarios generales con el prior y el capítulo de la casa en que residieran, nombrarían a un hermano que tuviese seis años de profesión como representante de la provincia, con el título de procurador.

Los comisarios generales de Indias, habiendo acabado sus oficios y dado cuenta a los nuevos electos, debían volver a España para rendir lo actuado frente al general. Es importante aclarar que el superior podía nombrar para el cargo de comisario a algún «morador de estas tierras». Al igual que en los demás oficios, quien acababa su período no podía ser reelegido sin que primero transcurrieran seis años.

A lo dicho, las Leyes de Indias agregaban otras consideraciones. En primer lugar, en ellas se mandaba a los virreyes, audiencias y gobernadores que velasen porque en todos los pueblos hubiera hospitales donde se curasen los pobres. Además, debían procurar que las fundaciones se hicieran junto a las iglesias y por claustro de ellas, siempre y cuando no se atendieran en los nosocomios enfermedades contagiosas. Para este último caso se preveía la construcción en lugares elevados, donde los vientos no permitieran el contagio ${ }^{19}$.

\footnotetext{
${ }_{18}$ Regla..., op. cit., pp. 86 y 87.

${ }^{19}$ Recopilación de leyes de los Reynos de Indias, mandadas a imprimir y publicar por la magestad Católica del Rey don Carlos II, nuestro Señor, Tomo Primero, Madrid, 1681, Tít. 4, L. I y II.
} 
Era deber de los virreyes de Perú y de Nueva España visitar periódicamente los hospitales de la capital o, en su defecto, los oidores los reemplazarían. Debían, en estas revistas, tomar estado de la situación económica en que estaban, y del servicio que se prestaba a los enfermos. En las ciudades más pequeñas se ocuparían de esta tarea los presidentes y gobernadores ${ }^{20}$.

Además de estas instrucciones generales, la ley V, libro I, título IV, de la $R e$ copilación de Indias con sus treinta disposiciones, se refiere en exclusividad a la religión de San Juan de Dios ${ }^{21}$. Se manda, primeramente, que en ninguno de los hospitales que estuvieran a cargo de los dichos religiosos hubiera un número mayor del necesario, el cual sería asignado por los virreyes o presidentes y las Audiencias reales, en conformidad con arzobispos y obispos. En las ciudades más pequeñas serían las autoridades civiles, en acuerdo con el prior del hospital, los encargados de fijar el número, el cual sería, en última instancia, aprobado por el Consejo de Indias ${ }^{22}$.

$\mathrm{Al}$ igual que en España, también en tierras americanas y en la provincia de Goa debía haber en los hospitales uno o dos religiosos, sacerdotes de la orden, que tendrían a su cargo la administración de los sacramentos, y deberían ser examinados previamente por el ordinario ${ }^{23}$.

Se prohibía expresamente a los juaninos fundar conventos y extender así su religión en los lugares donde sólo habían sido autorizados para levantar hospitales, los cuales debían tener iglesia y campana. Quienes gobernaran dichas instituciones no estaban autorizados a llevar el título de prior, sino el de hermano mayor ${ }^{24}$. Sin embargo, este último no se aplicó, y los documentos consultados permiten reconocer que para el uso corriente la denominación era la de prior.

«PERO LA PIEDAD PARA TODO APROVECHA... OCÚPATE EN ESTAS COSAS» $\left(1^{a}\right.$ TI. 4:8,15)

Aquéllos que quisieran vestir el hábito de San Juan de Dios debían prepararse para ello, al menos durante dos meses, en las casas de noviciado de la Orden. Como casas de noviciado en la Península se eligieron los conventos de Granada, Sevilla, Córdoba, Jaén, Madrid, Valladolid, Medina de Rioseco y Murcia, en España, y Lisboa y Yelves, en Portugal. En Nueva España, la casa se encontraba

\footnotetext{
${ }^{20}$ Ibidem, L. III.

${ }^{21}$ Lib. I, Tít., IV, 1. V, dada en Madrid por Felipe IV, el 20 de abril de 1652.

22 Ibidem, L. V, inc. 1,2,3.

${ }^{23} \mathrm{Ibidem}$, inc. 4, 5, 6.

${ }^{24}$ Ibidem, inc. 7, 8,9.
} 
en la ciudad de México ${ }^{25}$. Otras dos se encontraban en Lima y Panamá, las cabeceras y casa matrices de sus enormes provincias. Como tales, recibían la categoría de conventos. Dada la carencia de hermanos, las necesidades asistenciales y la enorme extensión del territorio, la corona permitió que los hospitales de Santa Fe de Granada, Santiago de Chile y el de la Villa Imperial de Potosí oficiaran como casas conventuales y de noviciado, y que los hermanos que allí se recibieren fueran enviados por igual a Tierra Firme, Islas de Barlovento, Granada, Nueva España y Perú, en el número que fuera necesario. Sin embargo, los superiores de estas últimas casas estarían subordinados a los comisarios de las referidas casas matrices ${ }^{26}$.

«HEME AQUí, OH SEÑOR, ENVÍAME A MÍ; ENVÍAME A LOS FINES DE LA TIERRA. ENVÍAME A LA MISMA MUERTE, CON TAL QUE ESTÉ EN TU SERVICIO.» (DAVID GRAINERD)

En la Chronologia hospitalaria leemos: «salieron algunas armadas que van a Nueva España y Tierra Firme y reparando en que necesitaban aquellos reinos de los ejercicios de la caridad, en orden al servicio y cura de los enfermos pobres, determinaron de sacar licencia de los reyes para pasar a fundar y dilatar nuestra religión» 27 .

Los primeros religiosos que vinieron a tierras americanas «no con ánimo de fundar, sino llevados de su activo celo, para ejercitar su instituto de hospitalidad con los enfermos ${ }^{28}$ fueron fray Francisco Hernández y Cristóbal Muñoz, con permiso de Felipe II. El rey decretó el 2 de diciembre de 1595 que se dejase pasar a las provincias de Cartagena, al padre Hernández y a cinco religiosos para los hospitales de Cartagena, Nombre de Dios y Panamá. No les dio, en principio, ningún sostén, ni siquiera el pasaje, para que viviesen de la caridad, pero luego, por decreto del 21 de diciembre del mismo año, mandó que por las reales cajas se les hiciese a los seis religiosos toda la costa del flete y sustento. Así fue como llegaron a Cartagena en 1596 y tomaron posesión de un hospital que ya existía en San Sebastián.

${ }^{25}$ En el fondo reservado de la Biblioteca Nacional de México se encuentra la Instrucción de novicios del orden de la hospitalidad, compuesta por el padre Agustín de Victoria, sacerdote de dicha orden. Las instrucciones llegaban a ser tan minuciosas que en el capítulo XXIII del citado libro, se enseñaba, incluso, la manera en que debían realizar dicha tarea para evitar el polvo: Habiendo batido el postrer colchón le volverá lo de arriba abajo y tenderá, y lo mismo hará con cada uno de los otros. Luego de sacudidas y tendidas las sábanas y mantas hará que se acueste el enfermo [...] acabadas de hacer las camas y dicho el responso por la comunidad que se suele decir por las ánimas serán los novicios los primeros en el limpiar de los vasos. Op. Cit., p. 57.

${ }^{26}$ Recopilación de las leyes de los reynos de Indias, op. cit., L. V, inc. 10, 11, 12, 13, 14.

27 J. SANTOS, Chronologia Hospitalaria y resumen historial de la Sagrada religión del glorioso patriarca San Juan de Dios. Aprobado por Pio V y confirmada por Sixto V, Paulo V y Urbano VIII, $2^{\circ}$ parte, Madrid, 1716, Libro Tercero, capítulo. II, p. 294.

${ }^{28}$ Archivo General de la Nación, México (en adelante AGN) Ramo: Historia; Vol: 14; ff: 260-264. 
Posteriormente fundaron allí otro hospital, el del Espíritu Santo, en el que se unieron los dos. Nuevos religiosos pasaron de España en 1608, 1613 y en 1617 para fundar en Nombre de Dios y Panamá.

Luego fue Cristóbal Muñoz quien pidió pasar a Nueva España, pues le pesaba la gran extensión del territorio, la cantidad de enfermos en él, y la falta de hospitales de religiosos juaninos que allí había ${ }^{29}$.

«El rey Felipe III, por decreto firmado en Valladolid el 1 de agosto de 1602, otorgó la licencia para que pasaran a dichas tierras el padre Muñoz y dieciséis religiosos, aclarando que el sustento y viaje de los religiosos fuese costeado por los haberes reales. Además, agregó, que dichos hermanos debían repartirse entre los territorios de México, La Habana y Tierra Firme. El permiso de fundación se amplió también para el Perú. El padre Muñoz tenía a su cargo la conducción y los destinos de cada miembro del grupo» ${ }^{30}$.

Pronto ocurriría en toda América y en las islas, lo mismo que en Europa, una vertiginosa expansión. El territorio fue dividido en 1633, como ya se dijo, en tres provincias. La provincia del Espíritu Santo abarcaba los territorios comprendidos en el Virreinato de la Nueva España y la Habana. Fue la más numerosa en cuanto a fundaciones; llegó a tener treinta y tres en el siglo XVII, incluyendo en ellas los dos hospitales filipinos. Las regiones mineras fueron las primeras beneficiadas, sobre todo las pertenecientes al reino de la Nueva Galicia.

La provincia de San Bernardo de Tierra Firme abarcaba las actuales repúblicas de Panamá y Colombia, y los primeros hospitales fundados fueron los de Cartagena, Santa Fe y Panamá. En total, para el siglo XVII, se contaba con once casas de asistencia. Un extenso territorio era cubierto por la provincia de San Rafael: el Virreinato del Perú. Desde el Callao hasta Valdivia (Chile), por la línea del Pacífico, y desde Lima hasta la Villa Real del Potosí, por el Altiplano, veinte hospitales prestaron servicio durante el siglo XVII. A las tierras del Plata hicieron su llegada con posterioridad, pero lograron asentarse sólo en Cuyo ${ }^{31}$.

\section{La orden de San JuAn de Dios en Nueva España}

Como queda visto, la Hospitalidad de San Juan de Dios se hallaba en pleno auge, y de toda América surgían peticiones reclamando su presencia. En Nueva España fue la de mayor extensión entre las demás órdenes hospitalarias.

\footnotetext{
29 J. SAnTos, Op. Cit., p. 432.

${ }^{30}$ AGN. Ramo: Historia; Vol.: 14; f: 260v.

${ }^{31}$ L. Ortega lázaro, O. H., Op. Cit., pp. 2-49.
}

Hispania Sacra, LIX

120, julio-diciembre 2007, 537-562, ISSN: 0018-215-X 
Desde el principio los cronistas y viajeros habían escrito sobre las condiciones de salud en estas tierras americanas, haciendo hincapié en ciertas zonas de clima difícil y hostil. Refiriéndose a Veracruz, uno de ellos decía que era «muy mal sana y en mi tiempo muchos marineros y soldados morían de las enfermedades que ahí reinaban, en especial los que no estaban aclimatados [a los cuales] les venían fiebres muy agudas de las que muy pocos escapaban» ${ }^{32}$. Ya a mediados del siglo XVI se encuentra en los relatos la mención de que las enfermedades se agravaban entre los meses de abril a agosto.

Entre las enfermedades, se puede mencionar la fiebre amarilla que atacaba en forma de epidemia periódica, estuvo presente durante toda la colonia y produjo enormes bajas en la población. Otra peste terrible, el sarampión, se produjo entre 1576-1577, y causó millones de muertes. El inicio del brote fue anotado por Bernal Díaz, quien dijo que en 1573 apareció en los barrios de la ciudad de México, y que era llamado por los indios cocoliztli. También fue descrita por el padre Cayetano Cabrera, quien señaló la relación entre la epidemia y la carestía de alimentos, la cual provocaba tantas bajas como la enfermedad misma ${ }^{33}$ $\mathrm{y}, \sin$ duda, la viruela.

Otra de las enfermedades que despobló a las comunidades indígenas fue el tifo, que junto al sarampión y a la varicela, comenzaron a presentarse en brotes epidémicos asociados con la viruela desde $1545^{34}$. A fines de 1595 y principios de 1596 se desató la última epidemia del siglo XVI, que fue mixta, pues consistió en sarampión, paperas y tabardillo. A este número deben añadirse la lepra y la tuberculosis, que dañaron por igual a toda la población.

A su vez, los españoles comenzaron a sufrir los efectos de ciertas enfermedades americanas: la leishmaniosis y tripanosomiasis, la verruga peruana, infecciones intestinales y varios tipos de parasitosis. El paludismo también afectó a los pobladores.

Para poner freno a los males mencionados surgieron en Nueva España los hospitales, que se perfilaron como instituciones para desposeídos. Se fundaron hospitales para indígenas ${ }^{35}$, para españoles y para negros y castas; y se estable-

32 E. Florescano y E. Malvido (comp.), Ensayos sobre la historia de las epidemias en México, México, 1982, Tomo I, p. 28.

33 Ibidem, p. 50.

${ }^{34}$ A. FARFÁn, Tractado Brebe de Medicina y de todas las enfermedades, hecho por el padre fray Agustín Farfán Doctor en Medicina, y religioso indigno de la orden de San Agustín, en la nueva España. Ahora nuevamente añadido. Dirigido a don Luis de Velasco, cavallero del hábito de Sanctiago, y virrey de esta nueva España, México, con privilegio en casa de Pedro Ocharte, 1592, p. 248 b.

${ }^{35}$ Consúltese la obra de C. Venegas Ramírez, Régimen hospitalario para Indios en la Nueva España, México, 1973. 
cieron instituciones para enfermedades específicas, contagiosas o no contagiosas, curables e incurables ${ }^{36}$.

El virrey don Juan de Mendoza y Luna, marqués de Montesclaros, dada la fama que gozaban los hospitalarios fundados por Juan de Dios, solicitó al rey Felipe III que permitiera la venida de ellos, permiso concedido por real cédula del año $1602^{37}$. La intención del virrey había sido entregar a la nueva religión el hospital del Espíritu Santo recién fundado, empero los religiosos tardaron mucho en llegar a México, ya que pasaron primeramente a Cuba. Allí fundaron un hospital y permanecieron todos juntos más de un año, para disponerse luego a proseguir el viaje. En La Habana el obispo dominico Juan de las Cabezas, les otorgó una casa y los ayudó con limosnas y ropa a fin de que pudieran llevar a cabo su misión.

Finalmente arribaron a la Nueva España el 18 de octubre de 1603, en número de cinco de los dieciséis que habían salido. Estos eran: fray Cristóbal Muñoz como prelado, fray Bruno de Ávila, fray Juan de Segura, fray Gonzalo de San Esteban y fray Juan Leonardo.

Este retraso ocasionó que el mencionado hospital del Espíritu Santo no les fuera entregado, pues lo habían dado ya a los hipólitos ${ }^{38}$. Por eso, durante algu-

${ }^{36}$ Consúltense las obras de Josefina Muriel, Hospitales de la Nueva España, México, Universidad Nacional Autónoma de México/Cruz Roja Mexicana, 1990. y Marcela SuÁrez, Hospitales y sociedad en la ciudad de México en el siglo XVI, México, Universidad Autónoma Metropolitana, 1988.

${ }^{37}$ Se reproduce a continuación la real cédula del 27 de marzo de 1602 :

«El Rey. Marqués de Montes Claros, pariente mi Virrey Gobernador y Capitán General de las Provincias de la Nueva España o a la persona o personas a cuyo cargo fuera el gobierno de ellas. El hermano Juan de Sequera de la orden y congregación de los Hermanos de Juan de Dios en nombre del hermano mayor y demás hermanos, que con licencia mía reside en esa Ciudad de México me ha hecho relación que se ha conseguido y consigue en esas partes a beneficio y utilidad y provecho que es notorio y que viendo esto y la necesidad que padecen de enfermedades en algunos lugares de este reino, así por la falta de hospitalidad como de médicos y de medicinas, han sido llamados, de diversas partes con ofrecimiento de hacerles toda comodidad para su sustento y darles hospitales donde puedan vivir y acudir al remedio y cura de las enfermedades que padecen españoles e indios, suplicándome aténtolo ya que por bula de su santidad les sería concedida licencia para fundar hospitales y hubiere necesidad de ellos, les mandase dar licencia y facultad para en los de donde en esas provincias fueran llamados los puedan fundar, o como en mi merced fuese y habiéndose visto en el mi Consejo Real de las Indias juntamente consta con cierta información de testigos de que hizo presentación, por donde consta lo susodicho, y por algunas cartas de prelados de las órdenes de esta provincia, en que me avisan de la necesidad que haya de la hospitalidad de los dichos hermanos en diversas partes de ella o del fruto grande que son, tiene por bien de dar la presente para vos, por lo cual os manda que vistas y consideradas con atención las partes y lugares donde los dichos hermanos son salidos para fundar hospitales, y no hallando inconveniente alguno notable, les deis licencia para ello [...] Yo el Rey.

«Cédula sobre la fundación de Hospitales de los Hermanos de San Juan de Dios», en A. M. CARREÑo, Cedulario de los siglos XVI y XVII, México, 1947, pp. 128-129.

${ }^{38}$ AGN. Ramo: Historia; Vol.: 14, f. 261r.

Hispania Sacra, LIX

120, julio-diciembre 2007, 537-562, ISSN: 0018-215-X 
nos meses vivieron en pobreza, sin tener casa propia, ni hospital en que servir, hasta que, a instancias del virrey, se les cedió con todos los derechos, el hospital de Nuestra Señora de los Desamparados (fundado en 1582 por Pedro López). Además se les encomendó la asistencia del hospital de San Lázaro, destinado a la curación de los leprosos ${ }^{39}$.

Muy pronto, las ciudades del interior solicitaron el envío de religiosos para fundar hospitales ${ }^{40}$. Dada la falta de hermanos, el padre fray Bruno de Ávila pasó a España en 1609 para traer algunos religiosos. Llegaron al año siguiente siete frailes, y por superior Ignacio Jiménez. Trajeron consigo una cédula real fechada en Madrid el 16 de agosto de 1608 donde se ordenaba que se les entregase también el Hospital Real de Naturales, cosa que no tuvo efecto, «por inconvenientes que se consideraron, o por desidia o falta de actividad de los religiosos como dice su cronista Juan Santos» ${ }^{41}$.

Ya en el actual territorio mexicano, se expandieron prontamente. El reino al cual llegaron en primer lugar fue al de Nueva Galicia, que «era de un temple cálido tolerable, pero que muchos pueblos, sobre todo los marítimos, son demasiado cálidos» ${ }^{42}$.

De la Mota y Escobar comienza su descripción del reino de Nueva Galicia por la ciudad de Guadalajara, ya que era la cabecera y centro del mismo. Residían allí el tribunal de la Real Audiencia y el tribunal eclesiástico del obispo. Contaba con una iglesia catedral y cuatro monasterios mendicantes, de las órdenes de Santo Domingo, San Francisco, San Agustín, y carmelitas; estaban instalados, también, los jesuitas, y monjas de la orden dominica. Además la ciudad tenía un hospital, el de San Miguel, donde se curaba todo tipo de enfermos, fundado con bienes decimales de la catedral y, por lo tanto, sujeto al obispo y al cabildo. Tenía médico, botica, barbero y capellán, pagados con salarios del mismo hospital. Había otro hospital llamado de la Veracruz, fundado por los conquistadores de la ciudad especializado en llagas y morbo gálico (nombre con el que se conocía a la sífilis); éste no tenía renta, sino que se mantenía con limosnas y de él se hicieron cargo los hermanos de San Juan de Dios cuando llegaran a dicha ciudad, el 11 de julio de 1606.

\footnotetext{
${ }^{39}$ La rivalidad entre las comunidades hospitalarias fue sutil pero presente, los hipólitos, Orden puramente novohipana instalados desde la segunda mitad del siglo XVI, pretendían tener el derecho exclusivo a la hospitalidad. Cfr. Ana Ortiz Islas, Los hospitales de la Orden de San Juan de Dios en la Nueva España: siglos XVII-XVIII, México, Innovación Editorial Lagares, 2004, pp. 131-132.

${ }^{40}$ Esto fue posible merced a una real cédula del 2 de abril de 1606, otorgada por el rey al marqués de Montes Claros, en la que se facultaba a éste para dar licencia a los religiosos de levantar sus centros asistenciales.

${ }^{41}$ AGN. Ramo: Historia; Vol.: 14: f. 262v.

42 A De la Mota y Escobar, Descripción Geográphica de los Reynos de Nueva Galicia, Nueva Vizcaya y Nuevo León, México, 1966, p. 19.
} 
En cuanto al clima, vuelve a referirse a él para decir que, «es muy cálido sobre todo desde abril a septiembre y muy malsano para aquellos que vinieran de regiones templadas y no estuvieran habituados al calor». En cuanto a las enfermedades que «generalmente engendra este temple son tercianas que dan con grandes fríos y fiebres y con grandes congojas [...] su cura es sangrías y purgas de cañafistola, y cosas frescas. Las enfermedades de gota y orina se encarnizan mucho en esta ciudad cuando dan que consumen al hombre hasta llevarle a la sepultura ${ }^{43}$. El valor de este párrafo es grande teniendo en cuenta que es una de las pocas menciones que se encuentran en las crónicas sobre las enfermedades más comunes en la región.

Colima distaba 150 leguas de la ciudad de Guadalajara y compartía su clima cálido e insano, debido a la cercanía del mar. Contaba con un convento de religiosos mercedarios, uno franciscano que administraba varios pueblos de indios, y un hospital de religiosos juaninos, hospitalarios de San Juan de Dios, el primero en instalarse en territorio novohispano ${ }^{44}$.

La hospitalidad de San Juan de Dios fue la única en actuar en Guadalajara hasta finales del año de 1704 en que llegaron los religiosos betlemitas. Luego de su asentamiento en la ciudad cabecera del reino prosiguieron los juaninos su expansión, ahora rumbo a la zona minera y muy poblada de Zacatecas.

\section{DE CANTERA Y PLATA: LAS PRIMERAS DÉCADAS DE VIDA EN ZACATECAS}

La muy noble y leal ciudad de Nuestra Señora de los Zacatecas se encuentra ubicada actualmente en el centro-norte de México, a una altitud de unos 2400 metros sobre el nivel del mar. Perteneció en la época de la colonia a la provincia y reino de la Nueva Galicia, y fue desde sus inicios un asentamiento español.

En 1548 se descubrieron las riquísimas vetas de San Bernabé, la Alvarada o San Benito y Pánuco. Este hallazgo produjo una gran emigración de las ciudades de México, Guadalajara y otras partes, que se inició dicho año y prosiguió durante varios más. Multitud de españoles acudieron atraídos por la fama del rico mineral. Su llegada exigió que se tomaran ciertas medidas para satisfacer las necesidades de una población en rápido crecimiento. La Audiencia de Guadalajara nombró al año siguiente un alcalde mayor, Pedro Mejía, y emitió una serie de ordenanzas para el gobierno de la ciudad.

${ }^{43}$ Ibidem, pp. 23-27.

44 J. Santos, Chronologia Hospitalaria... Op. Cit., p. 468. 
La influencia directa de la plata zacatecana no tardó en hacerse sentir. La necesidad básica de la nueva ciudad era el abastecimiento de alimentos para sus pobladores.

Otra de las necesidades de la población fue de orden espiritual. Para satisfacerla se había erigido, al mismo tiempo que se levantaba la ciudad, una parroquia sujeta al obispado de Guadalajara. Paralelamente fueron estableciéndose las distintas órdenes religiosas. Los primeros en llegar, los franciscanos, en 1558, fundaron en Zacatecas un hospicio ${ }^{45}$. A éstos se sumaron, en 1576, los agustinos. Los jesuitas habían llegado en 1574, pero recién en 1590 edificaron una pequeña casa con misioneros venidos de Guadalajara. En los primeros años del siglo XVII, 1604, se establecieron en la ciudad los dominicos. Cuatro años después haría su aparición la Orden de los juaninos.

Para responder a las necesidades de asistencia médica, la ciudad requirió de un hospital. El primero en fundarse, a instancias del vecino Diego Hernández de Silva ${ }^{46}$, fue el hospital de la Santa Veracruz.

La gran prosperidad y riqueza que las minas y el comercio produjeron, convirtió a la ciudad en una de las más importantes del país, con dos plazas y tres calles principales en las que se levantaban unas cuatrocientas casas, además de las del cabildo. Éstas eran de adobe, pero también las había de cal y canto, cubiertas de tajamanil: «las más de ellas son altas» ${ }^{47}$, es decir, de dos pisos.

Unos mil quinientos españoles y criollos poblaban Zacatecas, junto a más de tres mil negros e indios, sin contar la población ambulante. Es importante destacar que se habían establecido varias familias en estos sesenta años de vida de la ciudad, ya que se dice que, entre los españoles, más de mil serían casados, y de las otras naciones, más de dos mil. En cambio, eran muy pocos los extranjeros que residían en la ciudad, su número no llegaba a diez.

Un 29 de abril de 1608 se reunieron los cabildantes, en sesión ordinaria, para escuchar la propuesta del guardián del convento de San Francisco, que señalaba la necesidad de contar con un hospital en el que se asistiera a los pobres enfermos. También proponía que se aceptara la limosna de mil pesos de oro co-

\footnotetext{
45 Se trataba de un albergue provisorio en donde se acogía a los religiosos. En un principio fueron solamente tres, hasta tanto se levantó su convento. J. ARLEGHI, Crónica de la provincia de San Francisco de Zacatecas, México, Capítulo. II, s/f.

${ }^{46}$ Colección de documentos inéditos relativos al descubrimiento, conquista y colonización de las posesiones españolas en América y Oceanía, sacados en su mayor parte del Real Archivo de Indias, 42 vols., Madrid, 1864 y ss., T. I, 9, pp. 179-191.

${ }^{47}$ Idem.
} 
mún que una persona de la ciudad (Mateo de Rebolledo) ofrecía para fundar$\mathrm{lo}^{48}$. La discusión se prolongó hasta el mes siguiente ${ }^{49}$.

Las limosnas comenzaron a recaudarse a partir del día 19 de mayo y el 23 del mismo mes se resolvió la importante cuestión que el Cabildo de la ciudad estaba tratando. En esta reunión se dispuso lo siguiente: a) fundar un hospital; b) traer hermanos religiosos de la orden de San Juan de Dios para que allí curasen a los enfermos que se presentaran, y c) que para el funcionamiento del mismo se pidiera limosna a la ciudad. Para proceder a la fundación, se redactaron algunas ordenanzas que fray Alonso Pérez aceptó y firmó en conformi$\operatorname{dad}^{50}$.

Para la administración y funcionamiento del hospital en la ciudad se impusieron algunas condiciones como que el patronazgo lo tuviera la ciudad; que en él se recibieran todos los pobres enfermos que vinieren excepto los que padecieran lepra o el mal que dicen de San Lázaro y de San Antón ( o «mal de los ardientes»); que hubiera suficiente número de hermanos para que no faltara el servicio; que la limosna se pidiera todos los miércoles del año y así mismo, tierra adentro; que el hospital se entregara por lo menos a dos hermanos de asiento; que en caso de despoblarlo la Orden el edificio, y los bienes volvían a la ciudad; que los hermanos se encargaran de los enfermos sin ningún tipo de distinción y que por disposición de Leyes de Indias las cuentas las tomara el obispo con asistencia, no intervención, de los diputados de la ciudad.

Sobre los servicios que prestó el antiguo hospital de la Veracruz, o sobre las causas que lo llevaron a la ruina, no tenemos noticia alguna, pero lo cierto es que desapareció como tal, y que dicho espacio pasó a poder de los dominicos para la construcción de su convento cuando éstos llegaron a la ciudad, cuatro años antes que los juaninos. El Cabildo acordó, entonces, pedir permiso a las autoridades, no para levantar un nuevo hospital, sino solamente para trasladar el antiguo por las causas especificadas: lejanía y ocupación del sitio. El nuevo estaría erigido en otro lugar y con nuevas bases hospitalarias. Del anterior sólo heredaría el nombre, al que se le agregaría el de Nuestra Señora. Sin embargo pronto fue conocido por la población como hospital de San Juan de Dios, el cual quedó jurídicamente fundado el 9 de marzo de $1610^{51}$.

\footnotetext{
48 Archivo Histórico del Estado de Zacatecas, en adelante AHEZ, Fondo: Ayuntamiento; Serie: Actas de Cabildo. Libro 2, 29-4-1608, f. 211v.-212r.

49 AHEZ, Fondo: Ayuntamiento, Serie: Actas de Cabildo. Libro 2, 17-5-1608, f. 212v.

${ }^{50}$ AHEZ, Fondo: Ayuntamiento; Serie: Actas del_Cabildo. Libro 2, 23-5-1608, f. 213v.-214r.

${ }^{51}$ Archivo Histórico del Instituto Nacional de Antropología e Historia, AHINAH, Serie Guadalajara, rollo $18, \mathrm{n}^{\circ} 48$, leg. 27.

Hispania Sacra, LIX

120, julio-diciembre 2007, 537-562, ISSN: 0018-215-X
} 
El número de religiosos que generalmente hubo en este hospital de Zacatecas, osciló entre cinco y ocho ${ }^{52}$ salvo en sus inicios y en los momentos de decadencia.

Entre las personas que contribuyeron para la construcción del edificio hemos encontrado mencionadas a Luisa Ruano Ortiz, que cedió sus casas ${ }^{53}$, aunque no dejó renta ni limosna par la fundación porque no tenía caudal para ello, y a dos vecinos, Mateo de Jesús y Alonso Otero ${ }^{54}$ que, al tomar el hábito de la Orden. le donaron sus bienes materiales ${ }^{55}$.

El nuevo hospital se levantó al poniente del anterior, en un sitio cercano al arroyo que bajaba de la Quebradilla y de Tonalá Chepinque, «barrio» poblado por tarascos, y que se unía con el torrente principal en la parte sur de la ciudad. El edificio marcaba el límite de la expansión de la ciudad hacia el sur. Se erigió a los pies de un cerro llamado Loma de la Carnicería porque allí se encontraba el rastro -hoy colonia Sierra de Alica- y estuvo despoblado hasta que se levantaron unas pocas casas bien entrado el siglo XVII ${ }^{56}$.

La iglesia y el hospital estaban situados donde se encuentra en la actualidad el edificio de Telégrafos y la escuela para niñas, quedando la entrada del templo por la calle de la Merced Nueva, hoy Avenida Hidalgo, y el hospital con la entrada por la calle del Gorrero, hoy Avenida Juárez ${ }^{57}$.

Poco a poco se fueron levantando algunas construcciones hacia el suroeste del hospital, conformándose una plaza, con una extensión mayor que la de la

52 J. De Santa María Maraver, Piscina Zacatecana-/ Convento Hospital de N. P. /S. Juan de Dios reedificado. / Dedicación solemne /que se celebró el día 23 de febrero de este año /de 1718 siendo prior el R. P. Fray Antonio Lupercio, /quien la dedica a los sres. Capps. / D. Joseph de Urquiola, Alcalde Ordinario/ que fue de dicha ciudad, y diputado de su/ minería: y a D. Joseph de Rivera Bernardes, su Hijo., México, herederos de la viuda de Francisco Rodríguez Lupercio, en la Puente de Palacio, 1720. La cita se encuentra en el prólogo al lector, llamado «Descripción breve de la ciudad de Zacatecas». Maraver fue clérigo presbítero y capellán de dicho hospital. Él cita la existencia de seis religiosos para 1718 .

${ }^{5}$ Acerca de la primera, creemos que se trata de la misma Luisa de Herrera, mencionada como donante de una casa para la fundación del hospital con la obligación de 18 misas cantadas cada año.

${ }^{54}$ De Mateo de Jesús desconocemos su nombre verdadero, dado que ese fue el que tomó al profesar y comenzar a dirigir el hospital, en cambio, Alonso Otero quedó asentado como el benefactor que dejó un capital de 4541 pesos, con la obligación de 25 misas cada año. Archivo de Instrumentos Públicos de Jalisco, AIPJ, Serie: Libros de Gobierno de la Audiencia de Guadalajara. Libro 9. Año: 1797, ff. $1-8 \mathrm{r}$.

55 J. Santos, Chronologia Hospitalaria, Op. Cit., cap. LXXVIII, s/p.

56 P. BAKEWELL, Minería y sociedad en el México colonial. Zacatecas (1546-1700), México, 1984, p. 69.

${ }^{57}$ S. VIDAL, Edificios principales de la ciudad de Zacatecas, s/n, s/f, p. 21.

Hispania Sacra, LIX

120, julio-diciembre 2007, 537-562, ISSN: 0018-215-X 
plaza principal. Allí tuvieron lugar las primeras corridas de toros, dadas sus amplias dimensiones y la falta de pobladores en los alrededores ${ }^{58}$.

En 1625 se restauró la iglesia; se levantó a dos varas y media de alto y se instalaron maderos nuevos en las viguerías. También se estableció el altar mayor y se adornó la nave con cuatro retablos laterales ${ }^{59}$.

Dos registros tardíos, del siglo XVIII, ambos contradictorios, describen el edificio. Una de las relaciones fue hecha por el capellán de la orden, el presbítero Santa María Maraver, quien lo escribió en ocasión de la reedificación del hospital, en 1718. Sobre sus inicios dice: «... el sitio donde hoy habitan [estaba al momento de mudarse] tan indispuesto que se duda cómo habitaron, pues donde vivir cuatro religiosos con decencia, no venían siendo más que cuatro las celdas, y dos muy moderadas y pequeñitas y al presente inhabitables» ${ }^{60}$.

Continúa diciendo que contaba, además de sus cuatro celdas, con una enfermería de dieciséis camas para hombres. Juan Santos, en su Chronologia Hospitalaria, escrita dos años antes, 1716, presenta una imagen muy diferente, en la cual imprime opulencia y grandeza. En su escrito afirma que en momento de la edificación acudió la ciudad toda con sus limosnas, con las que se levantó un famoso hospital con enfermerías buenas y capaces, con oficinas y viviendas para los religiosos y una iglesia muy grande y hermosa. Enfatiza que allí se pusieron cincuenta camas con su respectiva ropa, «que hasta hoy se sustenta y conserva» ${ }^{61}$. Con respecto al número de religiosos, el dado por él asciende a ocho.

Ambas fuentes fueron escritas con intenciones diferentes. La de Maraver enfatiza la importancia de la obra de edificación, por lo tanto debe poner de manifiesto la necesidad que de ella había. En cuanto al escrito del cronista de la Orden, parecería ser menos confiable, ya que el objetivo de su obra, redactada presumiblemente desde España con informes recibidos, es la de describir cada una de las fundaciones desde los inicios hasta principios de siglo XVIII, destacando la laboriosidad de los religiosos y la importancia y buen funcionamiento de cada hospital.

El hospital contaba con una botica, y una enfermería para hombres. La licencia para vender medicinas a los vecinos de la ciudad dentro del hospital fue otorgada en agosto de 1612 por la Real Audiencia, y confirmada por el obispo ante un pedido realizado por el fraile Alonso Pérez ${ }^{62}$.

\footnotetext{
${ }^{58}$ R. Ramos DÁvila, Plazas, plazuelas y jardines de Zacatecas, Zacatecas, 1991, pp. 35-37.

${ }_{59}$ Archivo Parroquial de Zacatecas, Caja 113, Exp. 1, Libro de junta de los hermanos, junta del 29 de enero de 1626, f. 9. Citado por OrTIZ IsLas, op. Cit., p. 167.

$60 \mathrm{~J}$. de SANTA María Maraver, Ibidem.

61 J. Santos, Chronologia, Op. Cit., cap. LXXVIII.

${ }^{62}$ AHEZ, Fondo: Ayuntamiento; Serie: Hospitales, Año: 1798.
} 
La documentación permite saber que en los primeros años el hospital solamente se ocupó de atender a los hombres, ya que no contaba con sala de mujeres ni con medios suficientes para levantarla. Los accidentes de trabajo en las minas, caídas, golpes, afecciones pulmonares serían muy comunes ${ }^{63}$. Igualmente eran frecuentes las heridas de arma blanca ${ }^{64}$. Una recreación de la época reproduce el pintoresco aspecto que la ciudad de Zacatecas presentaba los sábados por la noche al desparramarse por ella los barreteros y demás trabajadores. Música ambulante, cantinas llenas, barajas, bailes en los que no escaseaba el licor. Todo ello provocaba riñas y escándalos que daban como saldo algunos heridos y hasta muertos ${ }^{65}$. Por último, en esta sociedad minera, con tantos hombres que se trasladaban de un mineral a otro buscando mejor suerte, la transmisión de las enfermedades venéreas estaba a la orden del día.

El pedido para levantar una sala para la atención de enfermas, lo realizó ante el Ayuntamiento, el prior Agustín de San Juan el 23 de abril de 1636:

«vista la necesidad grande que hay en esta ciudad de sala para que se curen mujeres pobres y cuán del servicio de Dios es; que en esta casa y hospital no se han recibido porque no ha habido comodidad [...] por hacer el dicho servicio a Dios y bien a las dichas mujeres de hacer la dicha sala y poner camas en el dicho hospital para el dicho efecto» ${ }^{66}$.

Tanto el comisario general de la Orden como el obispo y el corregidor de la ciudad compartían la idea de levantar la sala, y habían dado su consentimiento. Sin embargo esto no era suficiente, debido a que para ello se necesitaban fondos. Esta razón impulsó a fray Agustín de San Juan a pedir al Ayuntamiento que le otorgara una limosna a fin de comprar lienzos para confeccionar la ropa de cama, y todo lo necesario para llevar a cabo la obra. La respuesta del Cabildo no se hizo esperar, prometió donar doscientos pesos que obtendría en el «obligado de las carnicerías por cuenta de lo que deben de prometidos» ${ }^{67}$. Desde sus primeros años de vida el hospital hizo uso de los privilegios apostólicos concedidos a la orden: curar a los pobres enfermos que concurriesen, decir misa y ad-

${ }^{63}$ AHEZ, Fondo: Ayuntamiento; Serie: Hospitales, Año: 1731. Del mismo modo se atendían fiebres, humor gálico, llagas, diarreas, hidropesías, viruelas, dolor del costado y estómago, vómitos, gota, hernias, parálisis, obstrucciones, apostemas y cornadas de toro. AHEZ, Libro de Registro de enfermos de 1732-1742.

${ }^{64}$ Un registro, si bien tardío en lo que a nuestro trabajo se refiere, nos permite extrapolar ciertas conclusiones. Se trata de tres folios sueltos donde se asentaron las entradas y salidas de enfermos en el mes de enero de 1826. De 45 atendidos, 26 eran hombres. De ellos, 14 eran heridos en peleas donde tuvo que intervenir la policía; 5 fueron atendidos por enfermedades venéreas, y sólo 1 fue consignado como lastimado de la mina. Los 6 restantes sufrieron otro tipo de males, fiebres, pulmonía o «dolor de costado», etc.

65 C. Esparza, Cuentos, leyendas y costumbres del antiguo Zacatecas, México, 1992, pp. 20-22.

${ }^{66}$ AHEZ, Fondo: Ayuntamiento, Serie: Actas de Cabildo. Libro 3, 23 -4-1636, f. 328v.

67 Ibidem. 
ministrar los santos sacramentos. Así es que, teniendo siempre un cura capellán u otro sacerdote aprobado, administraron la Penitencia, la Eucaristía y la Extremaunción. Contó el hospital con una iglesia en la que se enterraban los que morían allí68.

En cuanto al alimento recibido, cada semana los asentistas debían enviar una cantidad específica de carne a todos los conventos y a la cárcel. De esta manera se aprovisionaba el hospital de un alimento vital por su riqueza en proteínas:

«De inmemorial tiempo a esta parte ha sido costumbre que todos los abastecedores de carne de la ciudad contribuyan semanalmente al hospital con un cuarto de res para ayuda» 69 .

El hospital no recibía renta fija, sino que subsistía de las limosnas que se recolectaban en la ciudad los días miércoles, y de las que se colectaban en los alrededores, fueran en dinero o en alimentos. Las limosnas que se percibían estaban en estrecha relación con los movimientos, avances y retrocesos de la minería en la región.

El autor de un informe enviado al Consejo de Indias en 1608 demuestra que la ciudad giraba alrededor de dos fuentes de riqueza: la producción de plata y el comercio, que, a su vez, respondía a los intereses de la primera. Dice que para ese entonces había en la ciudad unos veinte mineros, de los cuales cinco o seis eran muy ricos; además existían veinte haciendas que tenían ochenta ingenios de molienda para beneficio del metal, y sus propias recuas ${ }^{70}$. Otro indicador de la importancia de la minería y del prestigio político que adquirían los representantes del dicho gremio, es que, hasta donde hemos podido verificar (entre 1587 y 1680), la ciudad tuvo por costumbre elegir un minero por alcalde ordinario ${ }^{71}$.

El comportamiento de la producción minera zacatecana en las primeras décadas del siglo XVII (1610-1630) presentó un notable aumento, el cual coincidió con el momento del establecimiento de la orden y su hospital. Este desarrollo de la producción se debió principalmente a minas muy cercanas a la ciudad, sobre todo Vetagrande y Loreto, y a una adecuada disponibilidad de mercurio, factor crucial en la producción de plata por amalgamación ${ }^{72}$. Fueron años de bonanza para la población en general.

${ }^{68}$ AHEZ, Fondo: Ayuntamiento, Serie: Hospitales, Leg.: 1798.

${ }^{69}$ AHEZ, Fondo: Ayuntamiento, Serie: Actas de Cabildo. Libro: 1811-1812, 9-1-1812, s/f. Recordemos que aunque existía la prohibición de comer carne en Cuaresma y Semana Santa, los enfermos estaban autorizados a consumirla.

${ }^{70}$ Colección de Documentos inéditos..., Op. Cit., p. 179-191.

${ }^{71}$ AHEZ, Fondo: Ayuntamiento, Serie: Acuerdos de Cabildo. Libro 6, Año: 1680, f. 150.

72 A. BuRnes Ortiz, La minería en la historia económica de Zacatecas (1546-1876), Zacatecas, 1990, p. 50.

Hispania Sacra, LIX

120, julio-diciembre 2007, 537-562, ISSN: 0018-215-X 
Este florecimiento produjo un incremento en las limosnas e ingresos del hospital de San Juan de Dios. El hospital contaba con casas y censos y una renta de dos mil quinientos pesos, y una botica que suministraba más de dos mil pesos al año. A esa suma deben agregarse la recogida por los religiosos que pedían limosnas en la ciudad y salían a buscarla también por todos los reales de minas del reino, pasando, inclusive, al de Vizcaya. Sumaban todas las entradas un total de nueve mil pesos de renta para el año 163273; fue la época de mayor bonanza para la hospitalidad ${ }^{74}$.

Hay muy pocos datos sobre el proceso de adquisición o pérdida de los bienes raíces del hospital en estos primeros años. En uno de ellos se evidencia que don Juan de Villarreal había recibido de la Orden juanina a censo perpetuo, un medio sitio de terreno ubicado al sureste del hospital, con la condición de que procediera a levantar allí algunos aposentos ${ }^{75}$. El otro testimonio indica que poseían un terreno ubicado frente a la portería del hospital, adquirido por venta real realizada por el alférez Lorenzo Tostado el 26 de setiembre de 1628, siendo prior fray Mateo de $\mathrm{Haro}^{76}$.

Asimismo los juaninos cumplieron con una función muy importante de naturaleza cultural y social, ya que durante años las instalaciones pertenecientes a la Orden actuaron como centro de reunión y diversión de la sociedad zacatecana. En su plaza tuvieron lugar las primeras corridas de toros que se celebraron con motivo de alguna festividad y también funcionó como el primer teatro de la ciudad.

Al igual que en España, en las diversas ciudades de Nueva España fueron las instituciones de caridad las que gozaron de los beneficios rendidos por las representaciones teatrales para mantener a sus enfermos. En la capital, el Hospital Real de Naturales recibió una real cédula que lo autorizaba, y sólo a él, a dar funciones de teatro público para su sostenimiento, hecho que perduró hasta $1822^{77}$.

El mismo caso se repitió en varias ciudades del interior. Zacatecas también contó con su corral de comedias que servía como medio de financiamiento y sostén de la Orden de San Juan de Dios y su hospital ${ }^{78}$. Otro nombre que recibió el

${ }^{73}$ Esta información fue dada por pedido del padre fray Joseph de Medrano, prior del mencionado hospital, en el año de 1632. AHEZ. Fondo: Ayuntamiento; Serie: Hospitales. Año: 1655.

74 Éste era un monto muy importante si tomamos en cuenta como referencia los sueldos que se percibían en la época. Un corregidor, que era el empleo mejor pago en esta rica ciudad, recibía al año 1500 pesos, y la venta de dicho cargo llegó hacerse por 5000 pesos.

75 R. Ramos DÁvila, Op. Cit., p. 35

76 S . VidAL, Miscelánea, Zacatecas, 1972, p. 69.

77 J. Muriel, Hospitales de la Nueva España, México, 1993, pp. 127-148.

78 AHEZ, Fondo: Ayuntamiento, Serie: Hospitales, Año: 1655. 
corral fue el de «casa de comedias»; con él se designaba a los antiguos teatros españoles que se emplazaban en corrales o patios de los grandes inmuebles.

Por real cédula firmada en Madrid el 12 de julio de 1622, le fue otorgada a la orden de San Juan de Dios la exclusividad de las representaciones de comedias en la ciudad de Zacatecas:

«el privilegio de que en su corral, y no en otra parte alguna de esta ciudad se representen comedias, para que se dé en socorro de los enfermos que en él se curen, y mantienen» ${ }^{79}$.

Los comediantes viajaban, en época de festividades, por el interior del virreinato ofreciendo sus servicios. Un ejemplo de ello lo proporciona el Acta de Cabildo de la ciudad de Zacatecas del 24 de mayo de 1623:

«habiendo tratado la fiesta que se ha de hacer el día de Octava de Corpus Christi como es costumbre en esa dicha ciudad [...] se hagan dos comedias el día de Octava de Corpus Christi por la compañía que hay hoy en esta ciudad de farsantes [sic] y que haya danzas y lo demás que se pueda [...] y se encargue a dicho alguacil mayor que de parte de esta ciudad hable al vicario a curas y a los priores y guardianes de los conventos para que se hallen en la dicha fiesta» ${ }^{80}$.

A los ingresos del hospital ya mencionados, deben agregarse las exiguas y muy esporádicas contribuciones del Ayuntamiento y las voluntades testamentarias. En los protocolos testamentarios revisados, pertenecientes a los escribanos Lucas Fernández Pardo, Francisco Sánchez de Santa Ana, Felipe de Espinoza y Diego Vázquez Borrego, hemos encontrado sólo dos legados para la Orden: uno, de don Ignacio B. Bernárdez, quien pide que se les entregue 20 pesos el día de su entierro (cabe aclarar que contribuye con todas las órdenes habidas aquí, y la juanina es la que menos recibe $)^{81}$ y el otro del capitán Juan de Cossío Carrera, quien dice que de sus bienes se gasten 500 pesos en ropas de cama para los enfermos del hospital ${ }^{82}$.

\section{TIEMPOS DE INCERTIDUMBRE}

Los años de bonanza pronto se vieron opacados por problemas que afectaron la economía de la ciudad y su región. Las quejas de los vecinos, comprendi-

\footnotetext{
${ }^{79}$ AHEZ, Fondo: Ayuntamiento, Serie: Festividades, Subserie: Fiestas Civiles. Año: 1765

${ }^{80}$ AHEZ, Fondo: Ayuntamiento, Serie: Actas de Cabildo. Libro 3, 24-5-1623, f. 113v.

${ }^{81}$ AHEZ, Fondo: Notarías, Escribanía: Lucas Fernández Pardo, Protocolo 8. Año: 1698.

82 AHEZ, Fondo: Notarías, Escribanía: Lucas Fernández Pardo, Protocolo 10. Año 1700.
} 
dos conventos y demás entidades, no tardarían en escucharse. El prior del hospital, en un angustioso escrito de 1655, manifestó su pena y su miseria al reconocer que la pobreza general de la ciudad y la consiguiente baja de alquileres habían disminuido sus rentas por concepto de inmuebles y censos de 2250 a 1500 pesos. Los ingresos totales habían descendido de una manera pasmosa de 9000 a 2000 pesos $^{83}$.

Juan de Lanzarote, prior, informó que la botica seguía funcionando gracias a los cuidados y limosnas que fray Gerónimo de Aguirre recogía, y que el hospital todavía estaba en pie por los aportes de «algunas personas principales», cuyos nombres han quedado en el anonimato. El mismo documento también hace referencia al crecido número de pobres que concurrían al hospital para ser curados.

Una nueva y alarmante sequía, acompañada de epidemia de fiebre, se presentó en 1657, lo que motivó que se apelara nuevamente a los auxilios de la religión y otra vez se elevó un novenario a San Sebastián. A la epidemia de fiebre de 1657 se unió otra más terrible aún, que consistió en un fuerte dolor de costado, seguramente pulmonía, que ocasionó muchas víctimas. La misma volvió a darse dos años después:

«Y el año de 659 [...] sobrevino una epidemia pestilente de un ejecutivo dolor de costado, de que murieron por el mes de enero, en 26 días, millares de personas; ocurrieron a la dicha imagen [el Cristo Crucificado], haciéndole un novenario y el día último, que fue el 26 de enero, le sacaron en humilde procesión ${ }^{84}$.

Como la mayoría de las epidemias, ésta también se repitió de manera cíclica cada diez años, la de 1667 fue la última de este siglo XVII. Sin duda, estaban relacionadas con las sequías, falta de alimento y consecuentes enfermedades que se produjeron en la ciudad.

El hospital de San Juan de Dios se encontraba casi impotente para resolver la situación. Sin embargo, a pesar de las carencias, seguían recibiendo a todos los concurrentes, y tal como podemos leer en un informe, si las camas estaban todas ocupadas (algo frecuentísimo), se acomodaban a los que necesitasen hospitalización en las tarimas que había entre las mismas, «pues nunca se despide a ningún necesitado, por ser conforme a nuestro santo instituto» ${ }^{85}$.

La crisis, desde luego, afectó también a los espectáculos y las diversiones públicas. Dada la poca disponibilidad de dinero, aquéllos que solían concurrir a

${ }^{83}$ AHEZ, Fondo: Ayuntamiento; Serie: Hospitales; Año: 1655.

${ }^{84}$ M. De la Mota y Padilla, Historia de la Nueva Galicia, México, 1920, p. 360.

${ }^{85}$ AHINAH, Serie Guadalajara, rollo 18, $\mathrm{n}^{\circ}$ 48, leg. 27. 
las funciones presentadas en el corral de comedias y mantener con él a la orden, dejaron de hacerlo, lo que llevó a fray Lanzarote a lamentar:

«el corral de comedias que el dicho hospital tenía en que de ordinario representaba, está al presente caído, inhabitable, sin que haya en él más que un juego de barras de poca consideración con que tienen por ci[erto?] los testigos que no es competente al gasto que se tiene en el dicho hospital de puertas adentro en reparos que hay que obrar muy de ordinario, muchos aposentos y celdas de la vivienda que por inhabitable, amenazan ruina» ${ }^{86}$.

\section{NO HAY MAL QUE DURE CIEN AÑOS}

Un nuevo período de auge minero se produjo entre 1670 y 1690 debido en gran medida a las minas de Sombrerete, donde se descubrieron yacimientos de mineral rico. Esto trajo alivio a la ciudad y al hospital que recibió en 1685 las escrituras sobre la hacienda de San Nicolás Chapultepec, incluyendo los sitios de ganado mayor y menor, las construcciones y el cepo ${ }^{87}$. Poseían también una huerta de frutales llamada de San Nicolás, que contaba con una calera, casas y otros bienes. La vendieron el 7 de junio de 1709, según consta en acta notarial ${ }^{88}$.

Los caudales hospitalarios siguieron aumentando a fines del siglo, en 1691. Esta vez se trató de una donación hecha por Antonio de Buenrostro, un minero residente en esta ciudad y vecino de Chamacuero, poseedor de la mina de Nuestra Señora del Rosario en los cerros de Santiago. Es interesante mencionar que Buenrostro declaró que el acto piadoso por él realizado se debió a la gratitud que sentía por el hospital donde había sido curado con caridad y desvelo:

«Otorgo, hago gracia y donación irrevocable al Convento Hospital y sus religiosos del Sr. San Juan Bautista de esta ciudad de 12 barras de mina en la nombrada Nuestra Se-

\footnotetext{
${ }^{86}$ AHEZ, Fondo: Ayuntamiento, Serie: Hospitales, Año: 1655.

${ }^{87}$ Consultando los protocolos de los escribanos hemos podido reconstruir esta hacienda, que estaba ubicada en Jerez, la cual arrendaron en el año de 1679 a Juan de Soto y Velasco por seis años. En la escritura de arriendo se menciona que se hallaban reunidos el prior y los religiosos «al son de campana tañida como lo habemos de uso y costumbre». La escritura enunciada describe la hacienda, lo cual nos da una idea de su importancia: tierras de labor y sus caballerías; una sala de casa de hacienda de terrado con veinte viguetas; un jacal cubierto de zacate; dos corrales de piedra en los que se encerraba el ganado; treinta y ocho caballares, diecinueve yeguas, los demás caballos, un burro, setenta y cuatro reses vacunas, diez bueyes, nueve conejos, y las demás vacas, cincuenta y seis cabras con sus padres, cuatrocientas ovejas y siete padres ; una caseta con todo su apero necesario para servir; una mesa de pino pequeña y hachas. Todo ello debería ser devuelto al finalizar el arriendo.

88 AHEZ, Fondo: Notarías; Escribanía; Francisco Sánchez de Santa Ana; Libro: 2. Año: 1709, ff. 166-169.
}

Hispania Sacra, LIX

120, julio-diciembre 2007, 537-562, ISSN: 0018-215-X 
ñora del Rosario [...] y dicha donación hago graciosamente para que del producto de sus metales tengan los pobres del el sustento y asimismo dicho convento útil en lo que necesita» 89 .

Además de sus posesiones el hospital contaba con los ingresos que le proporcionaba la cofradía de la de la Santa Veracruz.

El siglo XVII se despidió con una década de declive económico, resultado del agotamiento de los ricos yacimientos de Sombrerete. La situación se hizo patente en el estado de deterioro del inmueble donde residían y atendían los hermanos juaninos, el cual no había sido nunca arreglado. El padre Maraver refiere que en 1693 se procedió a repararlo, y que fue entonces cuando se reedificó el templo y convento de San Juan de Dios. Maraver afirmaba que el nosocomio era «la casa más pobre» en Zacatecas ${ }^{90}$. Sin embargo, para el hospital todo finalizó de manera halagüeña, dado que ocurrieron dos hechos de suma importancia vinculados entre sí: la reedificación del templo y la canonización del entonces beato Juan de Dios, promulgada en Roma el 15 de julio de 1691 se declaró santo a Juan de Dios. En la Nueva España las buenas nuevas fueron celebradas con júbilo aunque con cierto retraso.

En esta ocasión también hubo una procesión. Ambos acontecimientos, canonización y reedificación, son los broches dorados de esta agitada centuria. Fue don Martín Berdugo de Ávila Aro y Velasco, tesorero de la Real Caja de la ciudad de Zacatecas, quien costeó la renovación del templo.

El sermón, predicado en ocasión de la reedificación del templo y, a su vez, en homenaje a san Juan de Dios, equiparaba a Juan de Dios con el personaje bíblico de Zaqueo, padre de los pobres, «ya que de la misma manera en que éste obró piedad con ellos, dejándoles sus bienes, se despojó el bendito Juan, convirtiendo su casa en templo de salud, y hospital para los dolientes». También utilizó la imagen de Abraham, padre de la Iglesia: «Cristo le intima: Ea Zaqueo, mira que te quiero para enfermero, deja los empleos de publicano, y entra en la escuela de Caritativo, porque quiero dar testimonio de que eres hijo de Abraham». «[Juan de Dios] era consuelo del desvalido, arrimo del necesitado, todo ojo para los ciegos, todo pies para los cojos, abogado continuo en las causas de los pobres» ${ }^{91}$.

89 AHEZ, Fondo: Notarías, Escribanía: Lucas Fernández Pardo, Protocolo 2. Año: 1691. Pensamos, en un principio, que encontraríamos más de dichas donaciones testamentarias, entendiendo la importancia de esta orden en la vida pública de la ciudad, pero la confrontación con los documentos hallados demostró que no era así.

90 J de Santa María MaraVer, «Descripción breve de la ciudad de Zacatecas», en Testimonios de Zacatecas, Zacatecas, 1992, p. 48.

${ }^{91}$ Sermón panegyrico que en la plausible y solemne fiesta de la reedificación de el templo de San Juan de Dios y publicación del testimonio de su canonización predicó el M. R. P. Pdo Fr, Juan de Espi- 
De esta manera se estrenó el templo renovado, entregando en manos de Dios a sus fieles siervos: «los que habitan como religiosos esta casa y como enfermeros tan devoto hospital [...] quiera Dios logren los hijos del caritativo patriarca, herederos de su espíritu, serafines abrasados en el noble ardor de su gozoso instituto, repetidas bendiciones en multiplicados alientos de tan noble ministerio» ${ }^{92}$.

\section{A MODO DE BALANCE}

La Hospitalidad de San Juan de Dios ha esparcido a sus frailes por el mundo con el fin de ejercer su ministerio. A principios del siglo XVII, considerado el de la expansión, llegaron a Nueva España y una vez allí, fueron solicitados desde la norteña ciudad de Nuestra Señora de los Zacatecas.

En una ciudad con enormes extremos de pobreza y riqueza, dominada por las familias adineradas de mineros, comerciantes y hacendados, a la Hospitalidad de San Juan de Dios le cupo la responsabilidad, y a la vez, el privilegio de trabajar cristianamente, sirviendo a sus semejantes sin distinción y prefiriendo a los pobres sobre los poderosos. Sus votos los comprometían a anteponer a los primeros, por considerarlos sus señores y amos.

El hospital que no recibía renta fija sino que subsistía con las limosnas de la ciudad y alrededores fue foco de serios problemas económicos ya que su vida dependía de los movimientos, avances y retrocesos de la minería en la región. En las épocas de bonanza, las rentas hospitalarias aumentaban, pero en las crisis mineras la situación económica llegó a ser desesperada.

Las limosnas solventaban sus gastos, que eran muchos: sueldo del personal no eclesiástico, comida, ropa de cama, mantenimiento del inmueble, y otros extras. Se recibían también donaciones, rentas, censos y capellanías.

Otro medio de engrosar sus arcas fueron los ingresos percibidos por el corral de comedias. El hospital se convirtió entonces en el espacio social y cultural que la ciudad disfrutó por más de un siglo y medio.

nosa, prior y vicario provincial del Convento de Predicadores de Santa Cruz de Zacatecas, en la dominica quarta de Adviento, diez y nueve de diciembre del año de 1694. Sacalo a luz el R. P. Fr. Juan de Dios, prior de el convento de el esclarecido patriarca S. Juan de Dios y lo dedica a su benefactor el señor d. Martín Berdugo de Ávila Aro y Velasco, tesorero de la Real Caxa de la ciudad de Zacatecas. Con licencia en México: por la viuda de Francisco Rodríguez Lupercio, Año de 1695. AHEZ. Fondo: Arturo Romo, Serie: Folletos, Caja: 2.

92 J de SANTA María MARAVER, «Descripción...», p. 48.

Hispania Sacra, LIX

120, julio-diciembre 2007, 537-562, ISSN: 0018-215-X 